\title{
A National Survey of Airway Management Training in United States Internal Medicine-Based Critical Care Fellowship Programs
}

\author{
Aaron M Joffe DO, Elaine C Liew MD, Hernando Olivar MD, Armagan HC Dagal MD, \\ Andreas Grabinsky MD, Matt Hallman MD, and Miriam M Treggiari MD MPH PhD
}

\begin{abstract}
BACKGROUND: Intensivists may be primarily responsible for airway management in non-operating room locations. Little is known of airway management training provided during fellowship. Our primary aim was to describe the current state of airway education in internal medicine-based critical care fellowship programs. METHODS: Between February 1 and April 30, 2011, program directors of all 3-year combined pulmonary/critical care and 2-year multidisciplinary critical care medicine programs in the United States were invited to complete an online survey. Contact information was obtained via FRIEDA Online (https://freida.ama-assn.org). Non-responders were sent automated reminders, were contacted by e-mail, or by telephone. RESULTS: The overall response proportion was $66 \%(111 / 168$ programs). Sixty-four $(58 \%)$ programs reported a designated airway rotation, chiefly occurring for 1 month during the first year of training. Thirty-five programs (32\%) reported having a director of airway education and 78 (70\%) reported incorporating simulationbased airway education. Nearly all programs $(95 \%)$ reported provision of supervised airway experience during fellowship. Commonly used airway management devices, including video laryngoscopes, intubating stylets, supraglottic airway devices, and fiberoptic bronchoscopes, were reportedly available to trainees. However, $73 \%$ reported $\leq 10$ uses of a supraglottic airway device, $60 \% \leq 25$ uses of intubating stylets, $73 \% \leq 30$ uses of a video laryngoscope, and $65 \%$ reported $\leq 10$ flexible fiberoptic intubations. Estimates of the required number of procedures to ensure competence varied widely. CONCLUSIONS: The majority of programs have a formal airway management program incorporating a variety of intubation techniques. Overall experience varies widely, however. Key words: critical care; education; endotracheal intubation; airway management. [Respir Care 2012;57(7):1084-1088. @ 2012 Daedalus Enterprises]
\end{abstract}

\section{Introduction}

Competence in airway management, particularly in emergency situations, is an essential skill for critical care physicians. In contrast to airway management within the operating room, which is most frequently necessitated by the need for general anesthesia, tracheal intubation in the ICU is presaged by urgency in the presence of active and/or suboptimally treated comorbid diseases associated with poor physiologic reserve and minimal margin of safety in the event an unanticipated difficult airway is encountered.

\footnotetext{
The authors are affiliated with the Department of Anesthesiology and Pain Medicine, Harborview Medical Center, University of Washington, Seattle, Washington; with the exception of Dr Liew, who is affiliated with the Department of Anesthesiology, University of Southern California, Keck School of Medicine, Los Angeles, California.

Supplementary material related to this paper is available at http:// www.rcjournal.com.
}

Under these circumstances the incidence of difficult intubation has been reported to be $8-13 \%,{ }^{1-3}$ with an attributed morbidity (eg, hypoxemia, hypotension, esophageal intubation, and aspiration) of nearly $40 \% .^{2-3}$ The odds of complications and death directly attributable to airway management increase several-fold the more the airway is manipulated with a notable inflection point after 2 attempts. ${ }^{1,4}$

Airway management training during an anesthesiology residency in either the United States or Canada has been surveyed several times..$^{5-7}$ The most recent survey, per-

\footnotetext{
The authors have disclosed no conflicts of interest.

Correspondence: Aaron M Joffe DO, Department of Anesthesiology and Pain Medicine, Harborview Medical Center, Box 359724, 325 Ninth Avenue, Seattle WA 98195-9724. E-mail: joffea@uw.edu.
}

DOI: $10.4187 /$ respcare. 01540 
formed by Pott and colleagues 7 in 2008, assessed not only temporal changes in the structure of airway management training, but the integration of simulation-based teaching and newer airway devices (eg, video-laryngoscopy, supraglottic airway devices, and extubation techniques) into established curricula, compared with surveys performed in $1995^{5}$ and $2003 .{ }^{6}$ Regarding non-anesthesia trained critical care physicians, a survey of program directors from the year 2006 reported that $64 \%$ of the respondents used simulation and 59\% required at least 10 intubations for proficiency. ${ }^{8}$ Aside from the lack of peer-reviewed journal publication (it was abstract form only), the survey was limited by an overall response of $37 \%$. The Accreditation Council for Graduate Medical Education program requirements for fellowship education in internal medicine-based critical care medicine state that the fellow "must demonstrate competence in airway management," but do not specify a minimum requirement for the type and number of supervised procedures, nor is "competence" defined beyond this rudimentary statement. 9

Thus, the primary aim of our survey was to delineate what airway management training is currently provided by internal medicine-based critical care fellowship programs. In particular, we were interested in the presence of designated airway management rotations and their duration, the types of teaching methods utilized, the integration of newer airway devices into the training experience of the fellow, the estimated number of supervised procedures performed during their training, and the numbers of supervised procedures required to become proficient with a given technique as assessed by the program directors.

\section{Methods}

A questionnaire with questions specifically addressed to non-anesthesia trained physicians was distributed using the Catalyst Web Tool (University of Washington, Seattle, Washington, http://www.washington.edu/lst/web_tools) (see Appendix A in the supplementary materials at http:// www.rcjournal.com), from February 1 through April 30, 2011. Survey content was adapted from a more extensive survey tool used to examine trends in airway management training among anesthesiology residency programs in the United States and Canada. ${ }^{7}$ Prior to distribution, the study questionnaire was pilot-tested by 6 experts in airway management. The group consisted of 3 anesthesiologists (HO, $\mathrm{AHCD}$, and $\mathrm{AG}$ ) and 3 anesthesiologist/intensivists (ECL, $\mathrm{MH}$, and MMT), all of whom are involved locally in airway management training for non-anesthesia trained providers (respiratory therapists, flight nurses, paramedics, emergency and internal medicine physicians) inside and outside the operating room. Specifically, they were asked to comment on whether the range of airway management techniques and response ranges included in the survey fairly represented the potential experience of a non-anes-

\section{QUICK LOOK}

\section{Current knowledge}

Outside of the operating room, intensivists are frequently responsible for airway management. The training in airway management provided to fellows in critical care medicine programs is not well described.

\section{What this paper contributes to our knowledge}

The majority of critical care fellowship programs include a formal airway management program, using a variety of intubation techniques. The individual experiences of fellows varies widely.

thesia based trainee, and on the functionality of the electronic survey tool, including a time estimate for its completion.

Program directors were asked to provide information regarding how the fellowship program provides airway management training. Additionally, they were asked to estimate the number of supervised uses of a variety of airway management devices performed by critical care fellows prior to graduation, and to provide their opinion as to how many of each airway management procedure they felt would be required for fellows to attain competency in its use prior to graduation. An announcement of the survey and an e-mail with a specific Web link were sent electronically to all internal medicine-based critical care fellowship program directors, using the contact information obtained via FRIEDA Online (https://freida.ama-assn.org). This included all 3-year combined pulmonary and critical care medicine and 2-year internal medicine-based critical care medicine fellowships. A reminder was sent automatically each Monday morning at 5:00 AM Pacific standard time for 3 months. The Catalyst tool automatically removes specific contact information once a response is registered to the site. The same e-mail cannot be used a second time, thus avoiding duplicate responses from the same program. In addition, investigator-initiated e-mail correspondence and telephone calls were made in attempts to achieve a minimum response of $\geq 60 \%$.

The University of Washington Human Subjects Division granted this study an exemption under category 2 from the requirements of the Federal Policy for the Protection of Human Subjects (45 CFR 46).

Data were summarized descriptively as frequency distributions. Exploratory analyses were conducted to compare variables between the 2- and 3-year fellowship programs, using the chi-square test, with $n-1$ degrees of freedom for contingency tables. Statistical significance was defined as a $P$ value $<.05$. Analyses were conducted 


\section{Survey of Airway Management Training in Critical Care Fellowship Programs}

using statistical software (Stata version 10, StataCorp, College Station, Texas).

\section{Results}

The survey was completed by 111 of $168(66 \%)$ programs overall; 76 3-year, 19 2-year, and in 8 cases (16 programs) where within the same institution one program director was responsible for both programs. In total, there are 134 3-year combined and 34 2-year internal medicinebased programs accredited by the Accreditation Council for Graduate Medical Education. Because there were no differences in the numbers of supervised airway procedures performed or the estimated number of supervised airway procedures needed to attain proficiency among the 3 -year and 2-year training programs, the results are combined to reflect all respondents. The results to all survey questions are reported, but have been summarized in some cases for clarity and relevance, due to the large number of questions and possible answers.

Characteristics of airway management training curricula for all respondents are presented in Table 1. A wide variety of airway management equipment was reportedly available for fellow training. In addition to traditional laryngoscopes (curved and straight blades), 92 (91\%) of programs responded that they had the laryngeal mask airway or equivalent available for training and use, in or out of the ICU; $62(61 \%)$ had intubating stylets; and $86(85 \%)$ had video laryngoscopes. Eighty-nine (88\%) of programs reported having a flexible fiberscope available in the ICU, and 65 (64\%) responded that fellows were taught fiberoptic intubation specifically for the purposes of airway management. The number of supervised airway procedures performed and the number of supervised airway procedures required to attain proficiency are presented in Tables 2 and 3 , respectively. The numbers of supervised uses of a video laryngoscope, supraglottic airway devices, and the fiberscope specifically for the purposes of airway management (asleep and awake fiberoptic intubation) were lower than that believed to be required to attain proficiency.

\section{Discussion}

The results of this survey indicate that the majority of programs offer dedicated rotations in airway management. Further, in addition to traditional methods of assuring minimal competency (setting a minimum number of procedures, submitting procedure logs to the program director), the majority of programs have incorporated mannequin and simulation based training into their curriculum, which may enhance airway management skills transfer to the clinical setting. ${ }^{10}$

A universally agreed upon minimal airways management skills set is unavailable. For anesthesia trainees in an operating room environment, a minimal skill set, including direct laryngoscopy, introducer stylets such as the Eschman
Table 1. Characteristics of Airway Management Training Curricula in Internal Medicine-Based Critical Care Fellowships*

\begin{tabular}{lc}
\hline \hline & no. $(\%)$ \\
\hline Respondents & $111(66)$ \\
3-year & $84(76)$ \\
2-year & $27(24)$ \\
Have a defined airway rotation & $64(58)$ \\
Year Fellowship Offered & \\
$\quad$ First & $50(78)$ \\
Second & \\
Third & \\
Throughout training & $53(48)$ \\
Duration of Rotation & \\
$<1$ month & $20(31)$ \\
1 month & $42(67)$ \\
2 months & $1(2)$ \\
Supervised Procedures Are Documented $\dagger$ & \\
Yes & $105(95)$ \\
No & $6(5)$ \\
Designated Airway Director & \\
Yes & $35(32)$ \\
No & $76(68)$ \\
Regularly Used Teaching Methods $\ddagger$ & \\
Didactic/reading & $73(66)$ \\
Required number of procedures & $61(55)$ \\
Simulation-based & $78(70)$ \\
Bedside & $96(86)$ \\
None used regularly & $6(5)$ \\
\end{tabular}

* Note: there are 168 accredited programs: 134 3-year combined pulmonary and critical care medicine, and 34 2-year multidisciplinary critical care medicine fellowship training programs. $\dashv$ Represents documentation from procedure log submitted to program director, billing records, or electronic medical record or automated anesthesia record.

$\ddagger$ Didactic/reading is summary of printed or required reading and scheduled didactics. Simulation-based is summary of Web or computer-based teaching, mannequin or simulation.

tracheal tube introducer, an extraglottic airway device such as the laryngeal mask airway, and a rigid video laryngoscope or flexible fiberoptic intubating system, has been recommended. ${ }^{11}$ At the very least, critical care trainees should be skilled in providing ventilation (either by face mask or an extraglottic airway) as well as tracheal intubation (either by direct laryngoscopy with the aid of an intubating stylet, if needed, or by rigid video laryngoscopy). Indeed, the overwhelming majority of respondents in our survey stated that these devices are commonly available and used in their respective ICUs.

Our results suggest that the majority of programs provide clinical airway training through a dedicated one-month airway management rotation and then subsequent supervised bedside procedures throughout the remainder of the 2- or 3-year training period. The value of this approach to initial skill acquisition and subsequent retention may be limited, however. For example, when ventilation by face mask has become difficult or impossible, insertion of a supraglottic airway such as the laryngeal mask is recommended. ${ }^{12}$ When used as a primary airway for elective 


\section{Survey of Airway Management Training in Critical Care Fellowship Programs}

Table 2. Estimated Number of Supervised Uses of Each Technique, on Average, That the Fellow Performs Prior to Graduation*

\begin{tabular}{|c|c|c|c|c|c|c|c|c|c|c|c|c|c|}
\hline \multirow{2}{*}{ Number range } & \multicolumn{13}{|c|}{ Estimated Number of Uses, no. (\%) } \\
\hline & $0-10$ & $0-25$ & $11-20$ & $11-30$ & $21-30$ & $21-50$ & $31-50$ & $26-50$ & $51-75$ & $>75$ & $76-100$ & $>100$ & Do Not Know \\
\hline Supraglottic airways & $81(73)$ & & $12(10)$ & & & $2(2)$ & & & $3(3)$ & & & & $11(10)$ \\
\hline Direct laryngoscopy $\dagger$ & & $46(41)$ & & & & & & $29(26)$ & $12(11)$ & & $3(3)$ & $2(2)$ & $10(9)$ \\
\hline Intubating stylets & & $61(60)$ & & & & & & $4(4)$ & $3(3)$ & & & & $29(26)$ \\
\hline Video laryngoscopy & $57(51)$ & & & $24(22)$ & & & $6(5)$ & & $2(2)$ & $2(2)$ & & & $12(11)$ \\
\hline Fiberoptic intubation $\ddagger$ & $72(65)$ & & $9(8)$ & & $1(1)$ & & $9(8)$ & & & & & & $12(11)$ \\
\hline \multicolumn{14}{|c|}{$\begin{array}{l}\text { * Sixty-seven percent reported } \leq 50 \text { laryngoscopies, } 73 \% \text { reported using a supraglottic airway device } \leq 10 \text { times, } 60 \% \text { reported using an intubating stylet } \leq 25 \text { times, } 73 \% \text { reported using a video } \\
\text { laryngoscope } \leq 30 \text { times, and } 65 \% \text { reported } \leq 10 \text { flexible fiberoptic intubations. For the purposes of data analysis, response fields with small numbers were combined. Additionally, response ranges } \\
\text { were not the same for all devices. Thus, some fields are blank. Numbers across each row may not equal } 1111 \text {, as response to the question was required, but not each field in the question. } \\
\dagger \text { Data has been combined for curved and straight blades. } \\
\text { ‡ Data has been combined for asleep and awake intubations. }\end{array}$} \\
\hline
\end{tabular}

Table 3. Number of Supervised Uses of Each Technique, on Average, That Program Directors Estimate Are Required for the Fellow to Attain Proficiency*

\begin{tabular}{|c|c|c|c|c|c|c|c|c|}
\hline \multirow[b]{2}{*}{ Number range } & \multicolumn{8}{|c|}{ Estimated Number of Uses, no. (\%) } \\
\hline & $0-9$ & $10-19$ & $20-39$ & $40-59$ & $60-79$ & $80-100$ & $>100$ & $\begin{array}{l}\text { Proficiency } \\
\text { Not Required }\end{array}$ \\
\hline Direct laryngoscopy (curved or straight blade) & $9(8)$ & $20(18)$ & $40(36)$ & $27(24)$ & $1(1)$ & $1(1)$ & $4(3)$ & $1(1)$ \\
\hline Intubating stylets (eg, Eschmann, Aintree) & $25(23)$ & $44(40)$ & $10(9)$ & $7(6)$ & $1(1)$ & & $1(1)$ & $15(14)$ \\
\hline $\begin{array}{l}\text { Video laryngoscopy (eg, GlideScope, } \\
\text { McGrath, Airtraq) }\end{array}$ & $22(20)$ & $44(40)$ & $26(23)$ & $5(4)$ & & & & $6(5)$ \\
\hline $\begin{array}{l}\text { Supraglottic airways (eg, laryngeal mask } \\
\text { airway, combitube, i-Gel) }\end{array}$ & $30(27)$ & $47(42)$ & $8(7)$ & $3(3)$ & & & & $7(6)$ \\
\hline Flexible fiberscope & $12(11)$ & $23(21)$ & $26(23)$ & $9(8)$ & $3(3)$ & & $2(2)$ & $8(7)$ \\
\hline Awake intubation & $17(15)$ & $42(38)$ & $26(23)$ & $5(4)$ & $1(1)$ & & $2(2)$ & $9(8)$ \\
\hline Airway anesthesia & $21(19)$ & $38(34)$ & $19(17)$ & $9(8)$ & $1(1)$ & & $1(1)$ & $14(13)$ \\
\hline Extubation techniques & $24(22)$ & $43(39)$ & $16(14)$ & $5(4)$ & $1(1)$ & & $1(1)$ & $14(13)$ \\
\hline
\end{tabular}

surgical patients, first generation laryngeal masks are reported to have a short-term learning curve of 15 insertions, ${ }^{13}$ but $73 \%$ of programs responded that trainees perform $\leq 10$ supervised uses. In addition, just over half of the respondents reported that the their fellows performed $\leq 10$ supervised uses of a video laryngoscope prior to graduation. While it has been reported that time to acquisition of skills required to perform video laryngoscopy is generally short (approximately 5 uses), the learning environment is typically a mannequin or an anesthetized patient in the operating room with normal airways. ${ }^{14,15}$ Even inside the controlled operating room environment when laryngoscopy is predicted or documented to be difficult, operators who have used the GlideScope $<20$ times have a reported first attempt success rate of only $66 \% .{ }^{16}$ In addition, a recent pre-hospital intubation study reported a significantly lower success rate in patients where the Airtraq optical laryngoscope was used as the first-line intubation technique, compared to traditional laryngoscopy. ${ }^{17}$ Of note, all intubations were performed by physicians board certified in anesthesiology or emergency medicine and had undergone prestudy instruction using simulation-based mannequin scenarios and 2-5 additional supervised Airtraq uses in the operating room.

Even when trainees attain early proficiency after an initial instruction period, performance may decay over time without periodic practice and feedback from more experienced providers. ${ }^{18}$ Thus, specific educational interventions targeted at maintaining advanced airway skills may be integrated into fellowship for extended periods of inactivity in airway management skill performance such as occur between a dedicated airway management rotation and subsequent ICU-based rotations, or during replacement of clinical with research activity.

We acknowledge our study has limitations. Surveys in general are subject to several forms of bias. We achieved $\mathrm{a}>65 \%$ response proportion, which is quite reasonable for electronic surveys of this type. However, non-response bias could affect our conclusions if the non-responding programs provided greater structure and experience to their fellows. This is unlikely, and, in fact, the numbers we report are more likely to be better than the average, as 


\section{Survey of Airway Management Training in Critical Care Fellowship Programs}

programs with less structure and experience might have been less likely to respond. In addition, bias due to measurement error could have occurred because of the way the questions were worded or due to forcing the respondents to assign frequency of training in pre-specified categories and entering their best guess. Further, responses could be biased toward what respondents might believe are more acceptable answers (social desirability), thereby overstating their fellows' actual experience. Lastly, as the survey was sent to the designated contact person listed by FRIEDA Online, we cannot confirm who actually completed the survey nor if the recipients were the most qualified responders to complete it. With these limitations in mind, we believe that the responses to our survey are, if anything, a possible overestimation of airway training instruction provided by internal medicine-based programs as a whole, leading to the conclusion that there is room for improvement beyond what is suggested by our results.

\section{Conclusions}

In sum, we report that the majority of internal medicinebased critical care training programs provide opportunity for formal airway management instruction, incorporating a variety of intubation techniques. However, experience varies widely, and it remains unclear as to whether competence in a minimal basic skills set is achieved at the completion of training. Future investigations should focus on determining a reasonable minimal airway management skill set for critical care trainees and construction of learning curves specific to the ICU for non-anesthesia trained providers.

\section{ACKNOWLEDGMENTS}

The authors gratefully acknowledge the assistance of The Board of Directors of the Association of Pulmonary and Critical Care Medicine Program Directors, as well as the members of the Association themselves who participated in the survey. To the many program assistants, coordinators, and people who knew people, we thank you as well.

\section{REFERENCES}

1. Schwartz DE, Matthay MA, Cohen NH. Death and other complications of emergency airway management in critically ill adults: a prospective investigation of 297 tracheal intubations. Anesthesiology 1995;82(2):367-376.

2. Jaber S, Amraoui J, Levering JY, Arich C, Cohendy R, Landreau L, et al. Clinical practice and risk factors for immediate complications of endotracheal intubation in the intensive care unit: a prospective, multiple-center study. Crit Care Med 2006;34(9):2355-2361.

3. Griesdale DE, Bosma TL, Kurth T, Isac G, Chittock DR. Complications of endotracheal intubation in the critically ill. Intensive Care Med 2008;34(10):1835-1842.
4. Mort TC. Emergency tracheal intubation: complications associated with repeated laryngoscopic attempts. Anesth Analg 2004;99(2): 607-613.

5. Koppel N, Reed AP. Formal instruction in difficult airway management. A survey of anesthesiology programs. Anesthesiology 1995; 83(6):1343-1346.

6. Hagberg CA, Greger J, Chelly JE, Saad-Eddin HE. Instruction of airway management skills during anesthesiology residency training. J Clin Anesth 2003;15(2):149-153.

7. Pott LM, Randel GI, Straker T, Becker KD, Cooper RM. A survey of airway training among US and Canadian anesthesiology residency programs. J Clin Anesth 2011;23(1):15-26.

8. Akers AS, Venkataraman R, Chelluri L. Airway managment outside of the operating room: a survey of critical care medicine program directors (abstract). Chest 2006;130(Suppl):88S.

9. ACGME. ACGME program requirements for fellowship education in critical care medicine (internal medicine). http://www.acgme. org/acWebsite/downloads/RRC_progReq/442_critical_care_surgery 01012009.pdf. Accessed April 25, 2012.

10. Naik VN, Matsumato ED, Houston P, Hamstra SJ, Yeung RY, Mallon JS, Martire TM. Fiberoptic orotracheal intubation on anesthetized patients: do manipulation skills learned on a simple model transfer into the operating room? Anesthesiology 2001;95(2):343-348.

11. Crosby E, Lane A. Innovations in anesthesia education: the development and implementation of a resident rotation for advanced airway management. Can J Anaesth 2009;56(12):939-959.

12. American Society of Anesthesiologists Task Force on Management of the Difficult Airway. Practice guidelines for management of the difficult airway: an updated report by the American Society of Anesthesiologists Task Force on Management of the Difficult Airway. Anesthesiology 2003;98(5):1269-1277.

13. McCrirrick A, Ramage DT, Pracilio JA, Hickman JA. Experience with the laryngeal mask airway in two hundred patients. Anaesth Intens Care 1991;19(2):256-260

14. Savoldelli GL, Schiffer E, Abegg C, Baeriswyl V, Clergue F, Waeber JL. Learning curves of the Glidescope, the McGrath and the Airtraq laryngoscopes: a manikin study. Eur J Anaesthesiol 2009; 26(7):554-558.

15. Di Marco P, Scattoni L, Spinoglio A, Luzi M, Canneti A, Pietropaoli P, Reale C. Learning curves of the Airtraq and the Macintosh laryngoscopes for tracheal intubation by novice laryngoscopists: a clinical study. Anesth Analg 2011;112(1):122-125.

16. Siu LW, Mathieson E, Naik VN, Chandra D, Joo HS. Patient- and operator-related factors associated with successful Glidescope intubations: a prospective observational study in 742 patients. Anaesth Intensive Care 2010;38(1):70-75.

17. Trimmel H, Kreutziger J, Fertsak G, Fitzka R, Dittrich M, Voelckel WG. Use of the Airtraq laryngoscope for emergency intubation in the prehospital setting: a randomized control trial. Crit Care Med 2011;39(3):489-493.

18. Kovacs G, Bullock G, Ackroyd-Stolarz S, Cain E, Petrie D. A randomized controlled trial on the effect of educational interventions in promoting airway management skill maintenance. Ann Emerg Med 2000;36(4):301-309.

This article is approved for Continuing Respiratory Care Education credit. For information and to obtain your CRCE

(free to AARC members) visit

www.rcjournal.com

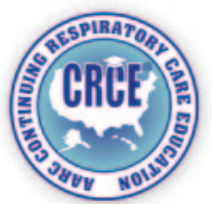

